\title{
EXPERIMENTAL RESEARCH ON OBTAINING EXTRACT WITH BIO- INSECTICIDAL/BIO-FERTILIZER ACTION FROM OCIMUM BASILICUM WITH APPLICATION FOR ORGANIC AGRICULTURE
}

\author{
Iulian Voicea ${ }^{1}$, Iuliana Gageanu ${ }^{1}$, Viorel Fatu ${ }^{2}$ \\ ${ }^{1}$ National Institute of Research-Development for Machines and Installations Designed to Agriculture \\ and Food Industry, Romania; ${ }^{2}$ Research-Development Institute for Plant Protection, Romania \\ voicea_iulian@yahoo.com, iulia.gageanu@gmail.com, fatu_viorel@yahoo.com
}

\begin{abstract}
Within the paper an experimental laboratory analysis is presented on the influence of a water-soluble extract with insect-repellent, fungistatic and growth stimulating properties on the growth of cucumber embryos during germination, on root growth in radishes, on root growth in tomatoes during the process of germination and on root growth in salad during germination. The extract with bio-insecticidal/biofertilizer activity was obtained by using an experimental model of innovative extractor that uses an extraction technique based on the pressure gradient (percolation) obtained by means of a hydro-pneumatic cylinder fed with compressed air from a $2.2 \mathrm{~kW}$ compressor, as well as the extraction technique under the action of ultrasound obtained using an ultrasonic generator with a maximum amplitude of up to $200 \mu \mathrm{m}$. The raw material introduced in the extraction vessel of the experimental model of extractor was represented by the green plant of Ocimum basilicum (common basil). The leaves of Ocimum plants produce an essential oil, which composition has been determined through gas chromatography (containing eugenol, eugenal, carvacrol, estragole, limatrol, caryophyllene), the presence of these compounds determining antimicrobial and insecticidal properties, as well as fertilizing action.
\end{abstract}

Keywords: bio-insecticide, bio-fertilizer, plant extract, percolation, ultrasound.

\section{Introduction}

Organic/bio/eco production is based on a type of agriculture that maintains and restores soil fertility, without the use of toxic chemical fertilizers and that keeps pests at bay without the use of pesticides and insecticides. Therefore, in organic agriculture it is imperative to use biofertilizers/bioinsecticides accepted by plants and that fall within the norms of the ecological concept $[1 ; 2]$.

After harvest, the products of organic farming are processed without the use of artificial ingredients, preservatives or radiation. In this context, the term organic refers to any product from organic farming; to obtain it, synthetic chemicals (herbicides, pesticides, artificial fertilizers or growth hormones) are not used, but natural, recycled organic products and the basic principle for cultivation is crop rotation [3,4]. Thus, the discovery of new substances and compounds with fertilizing/insecticidal action represents a continuous challenge for the field of agricultural scientific research in the $21^{\text {st }}$ century. The discovery of these new chemical compounds is possible by studying various plant extracts obtained from the variety of plants available on the surface of the earth. These plant extracts, depending on the biochemical composition can be used as biofertilizer/bioinsecticide substances for use in organic farming. For example, the strong smell of garlic, tobacco, rhubarb and other plants is repulsive to some insects. Hot pepper, alcohol, salt and other substances can burn or destroy pests. The oils suffocate certain insects, and the soap or ecological detergents added to the preparations have the role of making the substances of the solution stick to the leaves and stems $[5 ; 6]$.

Extraction is the operation of partial or total separation of the components of a mixture based on the difference in solubility in one or more solvents [7]. The process of extracting bioactive substances from medicinal plants takes place by achieving two basic principles, namely: dissolution of protoplasmic substances during contact between the solvent and plant cells and the actual extraction by penetrating the solvent into whole cells [8].

Modern technologies for obtaining bioactive substances from medicinal plants require: optimal extraction yields, but also a superior quality of the extracted substances, a quality as close as possible to their state in the plant product. The efficiency of conventional (Soxhlet extraction, maceration, percolation, distillation) and unconventional techniques (ultrasonic extraction, electrical pulses, microwave, supercritical and subcritical fluids, using extraction solvents) depends to a large extent on the authenticity of the plants, the chemical compositions of bioactive substances, the manner and sequence of plant processing operations, the nature and volume of the solvent used for extraction, temperature, extraction time and also on the size of the fragments [9]. 
Percolation is the process by which bioactive substances are extracted from plants, in cold state, using counterflow solvent. The process takes place as follows: before the solvent becomes saturated with extracted bioactive substances, it is displaced by another solvent layer in which the plant product undergoes a shortterm maceration and yields another part of the bioactive substances. This process is continuous, each portion of added solvent coming into contact with the plant product until its complete depletion [9; 10]. Ultrasoundassisted extraction is one of the most important techniques used for the extraction of valuable compounds from plant materials. This method is useful for the extraction of thermally sensitive constituents that are used in the food industry, in obtaining products with a biofertilizer/bioinsecticide role, body care products, cosmetics and the pharmaceutical industry. The ultrasonic extraction method is based on the principle of osmosis and ultrasonically activated diffusion, with an increased extraction efficiency and involves the use of ultrasound, with frequencies ranging from 20 to $2000 \mathrm{kHz}$, which increase the permeability of cell walls and produce cell lysis, thus favouring extraction of biologically active compounds [8]. The application of ultrasonic waves is a non-toxic, safe mechanical treatment, has high efficiency, yields quality products, has rapid processing time and is environmentally friendly $[7 ; 8]$.

\section{Materials and methods}

The water-soluble extract with bioinsecticide/biofertilizer activity was obtained using an experimental model of extraction equipment that has integrated 2 principles of extraction of bioactive compounds from plants, namely percolation (extraction under the action of a high-low alternating pressure gradient realized by means of a $2.2 \mathrm{kw}$ air compressor) and sonication (extraction technique under the action of an ultrasonic field).

The extraction method set using the PLC component part of the concentrated biofertilizer/bioinsecticide extractor is as follows: total extraction time 3600 seconds; high percolation extraction pressure: 1.1-1.4 bar; low extraction percolation pressure: 0.1-0.5 bar; number of cycles at high pressure: 4 cycles; number of low pressure cycles with quasi-dynamic pressure variation between 0.1 and 0.5 bar: 4 cycles; high pressure cycle duration: 600 seconds; low pressure cycle duration: 300 seconds with a duration of a quasi-dynamic cycle of 60 seconds, the pause of 60 seconds before and after the high pressure cycle and the pause of 60 seconds between the quasi-dynamic low pressure cycles; extraction temperature: $20^{\circ} \mathrm{C}$; amplitude of the ultrasonic field: 0-60 $\mu \mathrm{m}$; duration of low amplitude of 0-20 $\mu \mathrm{m}$ : 600 seconds; duration of high amplitude of 20-60 $\mu \mathrm{m}$ : 600 seconds; immersion of the ultrasound probe in the solvent: $35-45 \mathrm{~mm}$ and radiant surface of the ultrasound probe is $5.4 \mathrm{~cm}^{2}$.

The plant material used for the extraction processes of substances with bioinsecticide/biofertilizer action was represented by the green plant of common basil (Ocimum basilicum). From the point of view of the chemical composition, the volatile fraction represents, without a doubt, the most known component of the basil, depending on the chemotype and the investigated variety, the volatile oil content can have values between 0.04 and $0.70 \%$. The most important components of the oil are: estragole (methyl chavicol, over 87\% in some chemotypes), linalool (even over 75\%), eugenol (over 20\%), then ocimene, cineole, a number of sesquiterpenes and phenylpropane derivatives. The vegetable product also contains flavonoid derivatives (glycosides of quercetol and kemferol), caffeic acid, tannins, phytosterols and most likely some saponins. The chemical constituents of the volatile oil are: linalool, eugenol, estragole, 1,8-cineole, b-ocimene, b-caryophyllene, a-humulene, b-bergamotene, bbisabolengermacren-D, bisabolene derivatives, carvacrol, apigenin, apigenin-7-O-glucuronide, orientin. This extract was tested because it has a repellent action against the following pests found in greenhouses: mining fly (Liriomyza trifolii), greenhouse whitefly (Trialeurodes vaporarium), tobacco thrips (Thrips tabaci) and green lice of cucumbers (Aphis gossypii).

The seeds of vegetable plants selected for a first set of tests of efficacy and determination of the optimal concentration of plant extract in the final product for phytosanitary treatments were: cucumber seeds, tomatoes, radishes, lettuce, and they aimed at embryonic growth during germination and post germination growth of roota. In order to identify plant extracts with potential insecticide and also with the ability to stimulate germination and growth, a working protocol was developed that involves treating the seeds with conditioned extracts using a series of concentrations from 500 parts per million (ppm) to $5000 \mathrm{ppm}$, their germination in ventilated Petri dishes, determination of embryonic mass and measurement of the root length (Fig. 1). The evaluation of the root length was performed with the image 
analysis program Assess 2.0. Image for radish, lettuce and tomato seeds and with the electronic callipers for cucumber seeds.
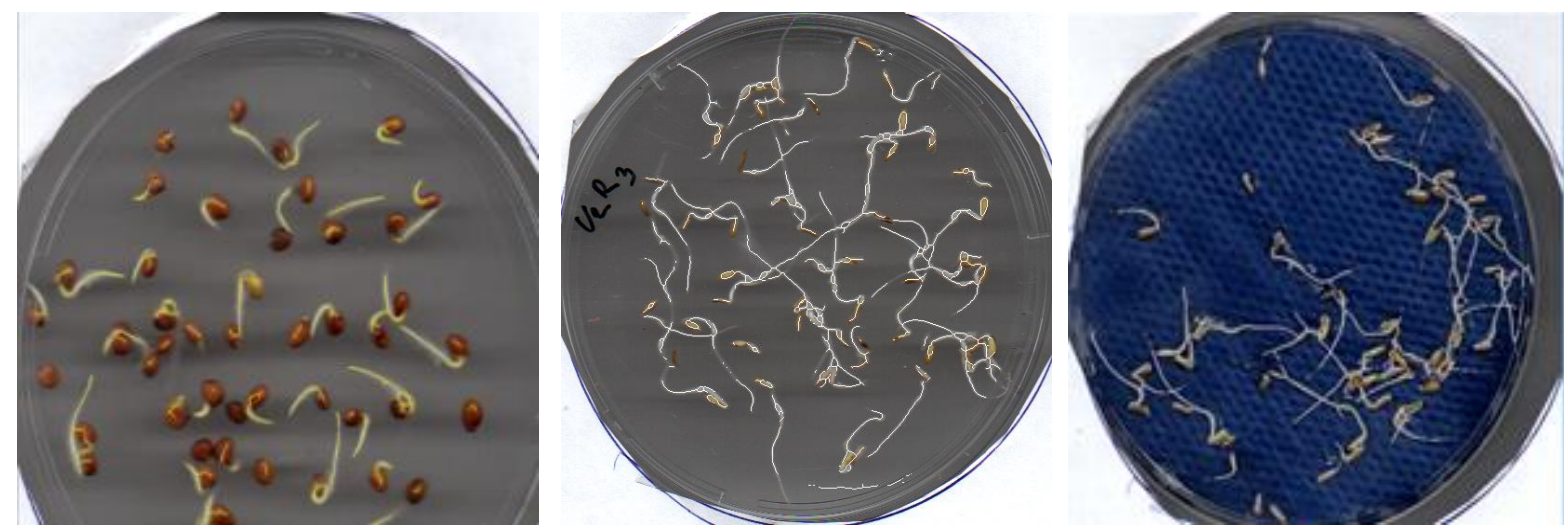

Fig. 1. Automatic determination of the length of radish roots (intensity 119-255), length of lettuce roots (intensity 105-145) and length of tomato roots (saturation 5-100)

The preparation of the batches for testing the effect of the water-soluble basil extract with biofertilizer/bioinsecticide activity at different concentrations is as follows: a batch of 1200 seeds (with their own unaltered microbiological load), the seeds are mixed well and divided into 24 batches of 50 seeds each (for small seeds, e.g., peppers, tomatoes) or 48 batches of 25 seeds each (large seeds e.g., corn, beans), label the Petri dishes ( $90 \mathrm{~mm} \times 16.2 \mathrm{~mm}$, with ventilation) from V1R1 to V6R4, or V6R8, the seeds are displayed in the Petri dishes, five industrial paper disks (three layers) of cellulose are inserted in the lid of the Petri dish. The treatment: weigh four batches of 50 or 25 seeds and determine the average mass, calculate the amount of mixture equivalent to $500 \mathrm{ppm}, 1000 \mathrm{ppm}, 2000 \mathrm{ppm}$, $3000 \mathrm{ppm}$ and $5000 \mathrm{ppm}$ for the average mass of seeds, add the dose test from the mixture of watersoluble basil extract in one part of the plate then homogenize with the seeds, place the cellulose discs on top of the seeds, soak the cellulose discs with $10 \mathrm{ml}$ of water then incubate at the optimum temperature for 3 days. Measurements and observations: germinated seeds are weighed and counted, length of the root/hypocotyl is measured using callipers or with the ASSES 2.0 system (scanner + PC + Software), the embryos are weighed, observations on the visible microbial activity are made, CIM (minimum inhibitory concentration) is determined.

\section{Results and discussion}

To test the action of basil extract on germination and root growth of cucumber seeds, five doses of water + volatile oil mixture were used for the test samples and only water for the control. After weighing the seed samples before the experiment, statistical analyses on the coefficient of variation were performed. Given that the seeds were of commercial origin, which requires careful sorting, the high quality was confirmed of the seed material by germination of over $80 \%$ and coefficient of variation of seed mass (batches of 25 seeds) less than 5\%. During the experiment it was found that starting with the value of the concentration of $1000 \mathrm{ppm}$ of the mixture, no visible microbial colonies were identified in the germination plates. At the value of the test concentration of the mixture of $3000 \mathrm{ppm}$, germination increase of $9 \%$ was obtained compared to the control, and the root growth registered an increase of 8.6 percent in the samples treated with 2000 ppm mixture (Table 1, Fig. 2).

Table 1

Testing of the action of water-soluble basil extract on the growth of cucumber embryos during germination

\begin{tabular}{|c|c|c|c|c|c|c|}
\hline M 25 seeds & V1 & V2 & V3 & V4 & V5 & V6 \\
\hline Dose ppm & 500 & 1000 & 2000 & 3000 & 5000 & 0 \\
\hline$\mu 1$ common basil esential oil & 0.31 & 0.61 & 1.22 & 1.83 & 3.05 & 0.00 \\
\hline$\mu 1$ mixture & 6.10 & 12.20 & 24.41 & 36.61 & 61.02 & 0.00 \\
\hline$\mu 1$ water & 654.92 & 648.82 & 636.61 & 624.41 & 600.00 & 661.02 \\
\hline$\mu 1$ oil/Kg seeds & 500 & 1000 & 2000 & 3000 & 5000 & - \\
\hline
\end{tabular}


Table 1(continued)

\begin{tabular}{|c|c|c|c|c|c|c|}
\hline M 25 seeds & V1 & V2 & V3 & V4 & V5 & V6 \\
\hline \multicolumn{7}{|c|}{ Seed weight } \\
\hline $\mathrm{R} 1$ & 0.663 & 0.644 & 0.699 & 0.638 & 0.641 & 0.644 \\
\hline $\mathrm{R} 2$ & 0.644 & 0.614 & 0.657 & 0.646 & 0.703 & 0.67 \\
\hline R3 & 0.643 & 0.675 & 0.656 & 0.646 & 0.679 & 0.634 \\
\hline R4 & 0.633 & 0.643 & 0.672 & 0.641 & 0.651 & 0.634 \\
\hline R5 & 0.634 & 0.663 & 0.66 & 0.661 & 0.616 & 0.652 \\
\hline R6 & 0.627 & 0.63 & 0.675 & 0.648 & 0.653 & 0.643 \\
\hline $\mathrm{R} 7$ & 0.605 & 0.674 & 0.649 & 0.661 & 0.635 & 0.652 \\
\hline $\mathrm{R} 8$ & 0.673 & 0.651 & 0.659 & 0.663 & 0.656 & 0.674 \\
\hline Mediate & 0.6403 & 0.6493 & 0.6659 & 0.6505 & 0.6543 & 0.6504 \\
\hline Standard deviation & 0.0211 & 0.0212 & 0.0158 & 0.0097 & 0.02676 & 0.0150 \\
\hline Coefficient of variation & $3.30 \%$ & $3.27 \%$ & $2.38 \%$ & $1.50 \%$ & $4.09 \%$ & $2.31 \%$ \\
\hline \multicolumn{7}{|c|}{ Embryo weight } \\
\hline $\mathrm{R} 1$ & 1.6 & 1.34 & 1.566 & 1.5 & 1.567 & 1.63 \\
\hline $\mathrm{R} 2$ & 1.342 & 1.469 & 1.428 & 1.444 & 1.489 & 1.355 \\
\hline $\mathrm{R} 3$ & 1.318 & 1.045 & 1.438 & 1.441 & 1.49 & 1.333 \\
\hline $\mathrm{R} 4$ & 1.508 & 1.45 & 1.817 & 1.46 & 1.237 & 1.421 \\
\hline R5 & 1.42 & 1.252 & 1.663 & 1.377 & 1.44 & 1.502 \\
\hline R6 & 1.477 & 1.689 & 1.498 & 1.778 & 1.473 & 1.56 \\
\hline R7 & 1.836 & 1.39 & 1.651 & 1.587 & 1.318 & 1.25 \\
\hline $\mathrm{R} 8$ & 1.665 & 1.412 & 1.967 & 1.626 & 1.69 & 1.688 \\
\hline Mediate & 1.521 & 1.381 & 1.629 & 1.527 & 1.463 & 1.467 \\
\hline Standard deviation & 0.1739 & 0.185 & 0.1887 & 0.1301 & 0.1396 & 0.1535 \\
\hline Coefficient of variation & $11.44 \%$ & $13.40 \%$ & $11.5 \%$ & $8.52 \%$ & $9.54 \%$ & $10.46 \%$ \\
\hline \multicolumn{7}{|c|}{ Germination percentage } \\
\hline Mediate & 87 & 82 & 90 & 87 & 85 & 81 \\
\hline
\end{tabular}

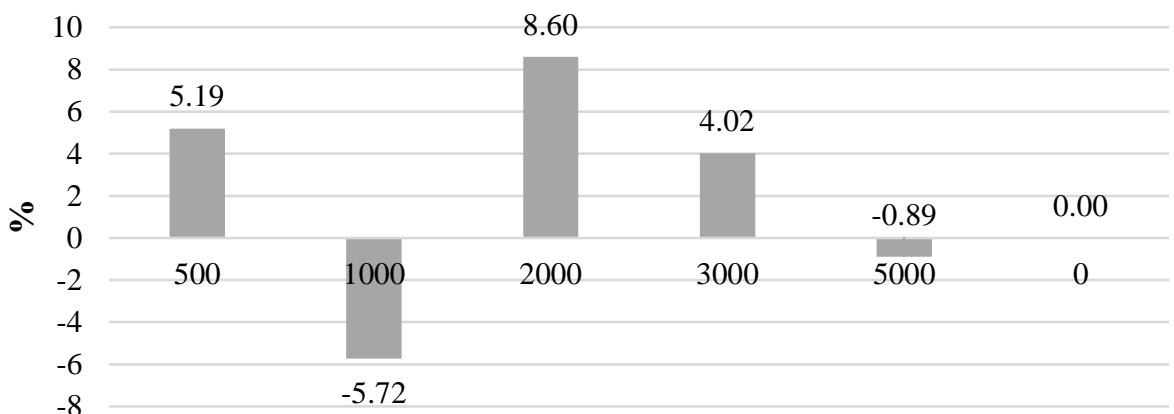

Concentration in ppm relative to dry seed mass

Fig. 2. Stimulating/inhibitory effect of volatile basil extract on root growth of cucumber seeds

In experiment 2, the aim was to evaluate the effect of the treatment with volatile basil extract on root growth during germination of radish seeds. The analysis of the coefficient of variation of the mass of the seed samples (50 seeds each) found the existence of values higher than 5\% which leads to a difficult interpretation of the treatment effect. To remove this difficulty, a mathematical relation was developed, highlighting the stimulatory/inhibitory effect using different biometric data types expressed as a percentage of the control:

$\%$ stimulation/inhibition $\left.=\left(\left(L_{\text {test }} * 100\right) / L_{\text {martor }}\right)-100\right)-\left(\left(M_{\text {test }} * 100\right) / M_{\text {martor }}\right)-100$

where $L_{\text {test }}-$ average root length test;

$L_{\text {martor }}$ - average root length control;

$M_{\text {test }}$ - seed mass before treatment test;

$M_{\text {martor }}$ - seed mass before treatment control. 
From Table 2, where the experimental data are presented, it can be deduced that a treatment concentration of $3000 \mathrm{ppm}$ volatile oil produced the strongest activity of inhibiting the appearance of microbial colonies nine days after the treatment. But in terms of repeatability of treatment, the value of $2000 \mathrm{ppm}$ had the lowest coefficient of variation. Thus, from the point of view of the robustness of the treatment, the range of values of the concentrations $2000-3000 \mathrm{ppm}$ allow a relaxation of the exigencies related to the dosage of the treatment without producing significant differences of results (Fig. 3).

Table 2

Testing of the action of water-soluble basil extract on radish root growth and antimicrobial effect during germination

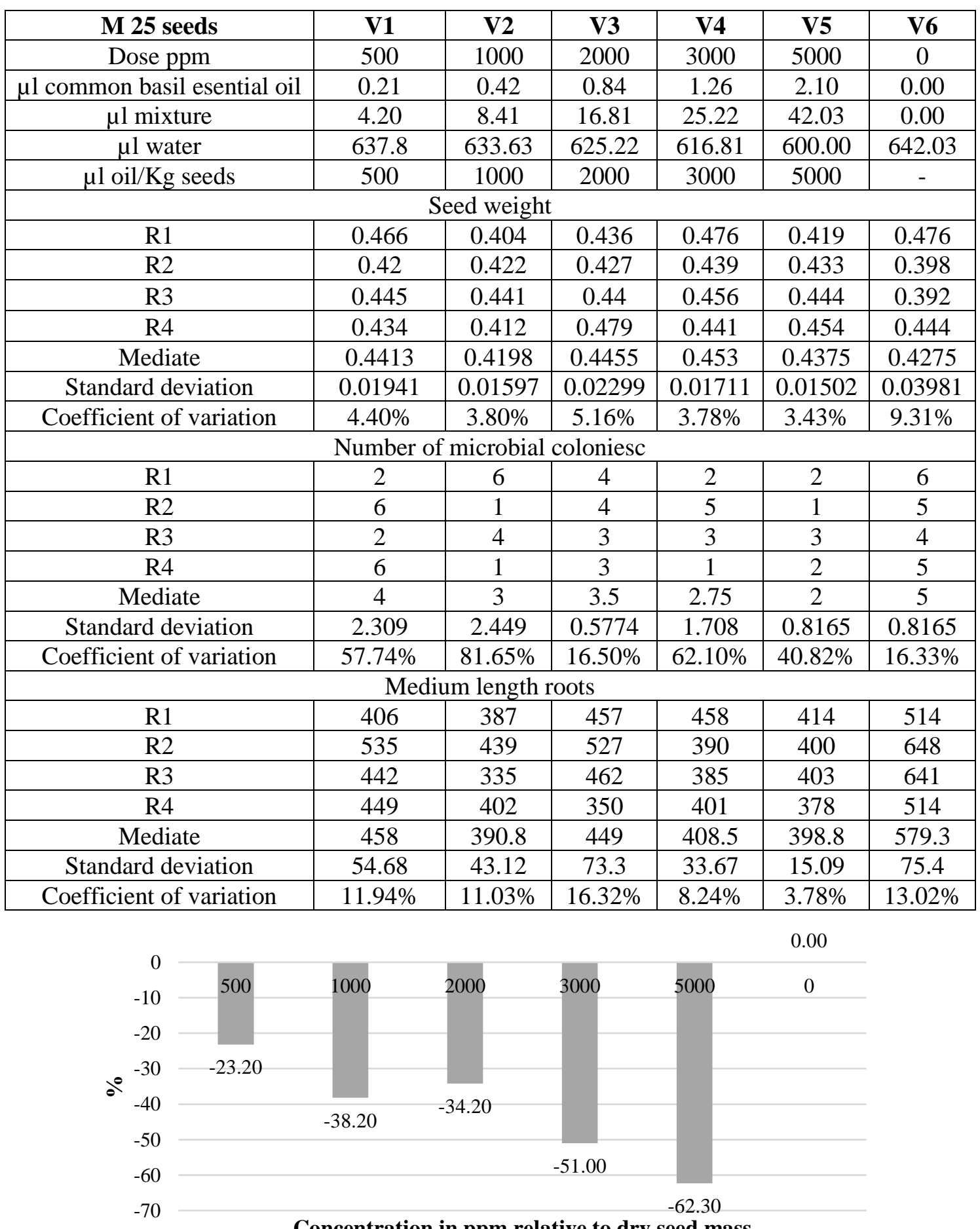

Concentration in ppm relative to dry seed mass

Fig. 3. Testing the stimulatory/inhibitory effect of the water-soluble extract of volatile basil oil on root growth at the time of germination of radish seeds 
From the point of view of growth stimulation, the volatile basil extract, used in the treatment of radish seeds, produced inhibitory effects on root growth at all concentrations compared to mature. A possible explanation could be given as a result of the presence of condensation on the test plate covers directly proportional to the dose tested. Thus, the volatile basil extract could overstimulate cellular respiration by generating heat to the detriment of construction biochemical processes.

In experiment 3, performing the treatment with volatile basil extract with biofertilizerstimulating/bioinsecticide - inhibiting activity on tomato seeds brought positive results for the concentrations of 2000 and $5000 \mathrm{ppm}$. However, the framing of the result from the $2000 \mathrm{ppm}$ treatment between two negative values of root growth stimulation (Img.) indicates either an experimental error or a node of metabolic cellular reactions in which a suppression of a metabolic pathway takes place. Given similar results from other experiments (around $1000 \mathrm{ppm} \mathrm{EU}$ ) cumulated with a slowdown in the increase of the coefficient of variation, it can be accepted as an explanation for the possibility of affecting a metabolic pathway that does not show mass accumulation (Table 3, Fig. 4).

Table 3

Testing of the action of water-soluble basil extract on root growth in tomatoes during germination

\begin{tabular}{|c|c|c|c|c|c|c|}
\hline M 25 seeds & V1 & V2 & V3 & V4 & V5 & V6 \\
\hline Dose ppm & 500 & 1000 & 2000 & 3000 & 5000 & 0 \\
\hline$\mu$ l common basil esential oil & 0.05 & 0.11 & 0.21 & 0.32 & 0.54 & 0.00 \\
\hline$\mu$ l mixture & 1.07 & 2.14 & 4.28 & 6.42 & 10.70 & 0.00 \\
\hline$\mu$ l water & 609.63 & 608.56 & 606.42 & 604.28 & 600.00 & 610.70 \\
\hline$\mu$ loil/Kg seeds & 500 & 1000 & 2000 & 3000 & 5000 & - \\
\hline \multicolumn{7}{|c|}{ Seed weight } \\
\hline R1 & 0.108 & 0.098 & 0.109 & 0.115 & 0.109 & 0.112 \\
\hline R2 & 0.107 & 0.112 & 0.123 & 0.11 & 0.11 & 0.119 \\
\hline R3 & 0.112 & 0.113 & 0.113 & 0.103 & 0.118 & 0.121 \\
\hline R4 & 0.105 & 0.113 & 0.114 & 0.107 & 0.112 & 0.115 \\
\hline Mediate & 0.108 & 0.109 & 0.1148 & 0.1088 & 0.1123 & 0.1168 \\
\hline Standard deviation & 0.002 & 0.007 & 0.005 & 0.005 & 0.004 & 0.004 \\
\hline Coefficient of variation & $2.73 \%$ & $6.74 \%$ & $5.15 \%$ & $4.65 \%$ & $3.59 \%$ & $3.45 \%$ \\
\hline R1 & Medium length roots & \\
\hline R2 & 1252 & 1303 & 1409 & 1424 & 1456 & 1682 \\
\hline R3 & 993 & 1620 & 1226 & 1179 & 1538 & 1487 \\
\hline R4 & 1090 & 1387 & 1101 & 1363 & 1660 & 1383 \\
\hline Mediate & 1385 & 1446 & 1532 & 1257 & 1412 & 1271 \\
\hline Standard deviation & 1180 & 1439 & 1317 & 1306 & 1517 & 1456 \\
\hline Coefficient of variation & 173.5 & 134.2 & 191.2 & 109.1 & 109 & 174.7 \\
\hline
\end{tabular}

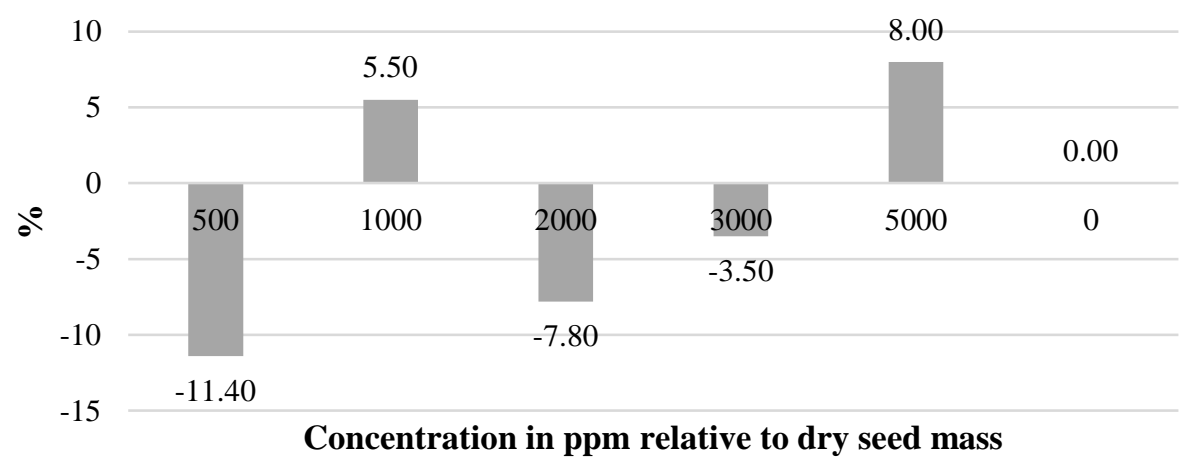

Fig. 4. Testing the stimulatory/inhibitory effect of the water-soluble extract of volatile basil oil on root growth at the time of germination of tomato seeds 
In Experiment 4 (Table 4, Fig. 5), the evaluation of the action of the volatile basil extract on the root growth of lettuce embryos at the time of germination was performed with difficulty due to the very small seed size and large differences between individual physical dimensions, although the coefficient of variation of the average mass of 50 seeds was small. To remove this difficulty, a mathematical relation was developed that highlights the stimulatory/inhibitory effect using different biometric data types expressed as a percentage of the minimum and maximum values in the set of data values that includes all samples:

$\%$ stimulation/inhibition $=\left(\left(L_{\text {test }}-L_{\min }\right) /\left(L_{\max }-L_{\min }\right) * 100-\left(\left(M_{\text {test }}-M_{\min }\right) /\left(M_{\max }-M_{\min }\right) * 100\right)\right.$

where $L_{\text {test }}-$ average length of the sample root;

$L_{\min }-$ minimum average length of the data set (test + control);

$L_{\max }$ - maximum average length of the data set (test + control);

$M_{\text {test }}$ - average mass of seeds in the sample;

$M_{\min }-$ minimum average seed mass in the data set (test + control);

$M_{\max }$ - maximum average mass of seeds in the data set (test + control).

Testing of the action of water-soluble basil extract on root growth

Table 4 in lettuce during germination

\begin{tabular}{|c|c|c|c|c|c|c|}
\hline M 25 seeds & V1 & V2 & V3 & V4 & V5 & V6 \\
\hline Dose ppm & 500 & 1000 & 2000 & 3000 & 5000 & 0 \\
\hline$\mu$ l common basil esential oil & 0.02 & 0.05 & 0.09 & 0.14 & 0.23 & 0.00 \\
\hline$\mu$ l mixture & 0.45 & 0.90 & 1.81 & 2.71 & 4.52 & 0.00 \\
\hline$\mu$ l water & 604.0 & 603.6 & 602.7 & 601.8 & 600.0 & 604.5 \\
\hline$\mu$ l oil/Kg seeds & 500 & 1000 & 2000 & 3000 & 5000 & - \\
\hline \multicolumn{7}{|c|}{ Seed weight } \\
\hline R1 & 0.047 & 0.048 & 0.044 & 0.049 & 0.051 & 0.045 \\
\hline R2 & 0.046 & 0.047 & 0.047 & 0.048 & 0.051 & 0.045 \\
\hline R3 & 0.045 & 0.049 & 0.047 & 0.044 & 0.046 & 0.046 \\
\hline R4 & 0.044 & 0.049 & 0.040 & 0.048 & 0.050 & 0.049 \\
\hline Mediate & 0.0455 & 0.0482 & 0.044 & 0.0472 & 0.049 & 0.0462 \\
\hline Standard deviation & 0.0013 & 0.0010 & 0.0033 & 0.0022 & 0.0024 & 0.0019 \\
\hline Coefficient of variation & $2.84 \%$ & $1.98 \%$ & $7.45 \%$ & $4.69 \%$ & $4.81 \%$ & $4.09 \%$ \\
\hline \multicolumn{7}{|c|}{ Medium length roots } \\
\hline R2 & 802 & 920 & 837 & 750 & 892 & 834 \\
\hline R3 & 752 & 870 & 805 & 735 & 833 & 880 \\
\hline R4 & 656 & 890 & 746 & 625 & 833 & 768 \\
\hline Mediate & 891 & 835 & 771 & 648 & 731 & 860 \\
\hline Standard deviation & 775.3 & 878.8 & 789.8 & 689.5 & 822.3 & 835.5 \\
\hline Coefficient of variation & 98.11 & 35.68 & 39.71 & 62.22 & 66.89 & 48.78 \\
\hline
\end{tabular}

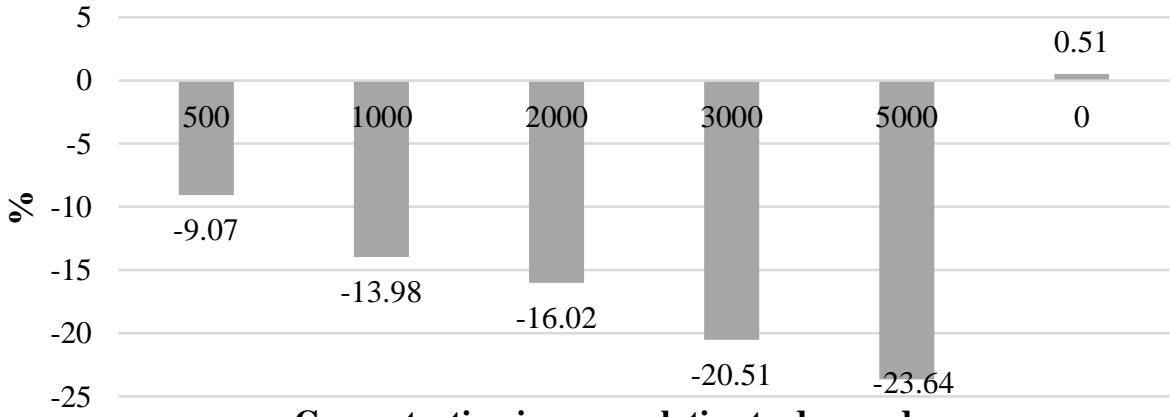

Concentration in ppm relative to dry seed mass

Fig. 5. Testing the stimulatory/inhibitory effect of the water-soluble extract of volatile basil oil on root growth at the time of germination of lettuce seeds 


\section{Conclusions}

Following the experiments, the following conclusions can be drawn:

1. treatment of cucumber seeds (Wisconsin variety SMR58) with a mixture of water + water-soluble extract of volatile basil oil + gelatine or CMC gave positive values for microbial control in the rhizosphere simultaneously with the stimulation of germination and root growth. These experimentally observed properties on insect control demonstrate that basil (Ocimum basilicum) extracts can be used in the simultaneous production technology of bioinsecticides and biofertilizers for cucumber cultivation.

2. treatment using water-soluble volatile basil oil on radish seeds is not recommended, at least when the soil temperature is higher than $18^{\circ} \mathrm{C}$ (the temperature set for germination was $20 \pm 2{ }^{\circ} \mathrm{C}$ ).

3. use of water-soluble basil volatile essential oil in a concentration of $5000 \mathrm{ppm}$ in the treatment of tomato seeds before sowing is an alternative method of fungicide treatments and a way to protect the rhizosphere from pests in the soil.

4. based on the experimental data (Table 4), after applying the mathematical relation (2), it can be stated that the use of volatile basil extract is not recommended in the treatment of lettuce seeds before sowing, because it produces an inhibition of root growth between $9 \%$ and $23 \%$.

\section{Acknoledgements}

The work has been funded by the Sectorial Programme MADR - ADER 2019-2022, ADER 25.4.1. Technology for obtaining biofertilizers and/or bioinsecticides for ecological production systems, Contract No. ADER 25.4.1/24.09.2020.

\section{References}

[1] Popescu C., Voicea I., Vlăduţ V. Influence of breakage process on increasing the extraction yield of medicinal plants bioactive substances, Romanian Biotechnological Letters, Vol. 20, No. 4, 2015, pp. 10561-10571.

[2] Agnieszka S, Katarzyna C. Biofertilizers, Organic Farmer, 2019, pp. 182-194.

[3] Arun KS. - Bio-fertilizers for sustainable agriculture. Mechanism of P-solubilization, Agri bios Publishers, Jodhpur, India, 2007, pp. 196-197.

[4] Ionescu M., Voicu Gh., Biriş S.Şt., Vlăduţ V., Ungureanu N., Ştefan E.M., Dincă M., Matache M. - Oil extraction using a vertical press with piston, Proceedings of the 44 International Symposium on Agricultural Engineering “Actual Tasks on Agricultural Engineering”, pp. 249-258, 2016, ISSN 1333-2651.

[5] Mishra DJ, Rajvir S., Mishra U.K., Kumar S.S. Role of bio-fertilizer in organic agriculture: a review, Research Journal of Recent Sciences, Vol. 2, ISC-2012, pp. 39-41.

[6] José D. Et all. - Future Perspective in Organic Farming Fertilization, Organic Farmer, 2019, pp. 210-220.

[7] Pruteanu A., David L., Muscalu A., Vlăduţ V. Quality of thymus (Thymus vulgaris) screening process in order to obtain bioactive extracts, Proceedings of the 44 International Symposium on Agricultural Engineering “Actual Tasks on Agricultural Engineering”, pp. 299-310, 2016, ISSN 1333-2651.

[8] Romdhane M., Gourdon C. Investigation in solid-liquid extraction: influence of ultrasound. Journal Chemical. Engineer, nr. 87, 2002, pp. 11-19.

[9] Pruteanu A., Popescu C., Vlăduţ V., Găgeanu I. Biochemical analysis of some vegetal extracts obtained from indigenous spontaneous species of (Thymus serpyllum L.), Romanian Biotechnological Letters, Vol. 23, No. 5, 2018, pp. 14013-14024.

[10] Popescu (Popiniuc) C., Popescu C., Manea St., Vlăduţ V., Voicea I., Covaliu C., Abbas H., Dune A., Lupuleasa D. The influence of extraction solvent on the active principles content of portulaca oleracea native species, Revista De Chimie 69 (10)/2018, pp. 2682-2692, (IF: 1.605). 